\title{
General introduction
}

\section{INTRODUCING OPEN INNOVATION}

The process of innovation is dynamic and complex, and entrepreneurs have to deal with, and adapt to, the ever-changing environment in which they operate. Many textbooks, therefore, start by listing innovation models from every conceivable perspective (see, for example, Dodgson et al., 2008; Schilling, 2008; Tidd et al., 1997; Afuah, 1998; Trott, 1998; Rothwell, 1992), or by showing these models' sequential rise and fall (for example, Chesbrough, 2006a; Rothwell, 1992; Rothwell and Zegveld, 1985; Trott, 1998). Open innovation has been welcomed as the most recent member in this family of models. Authors rarely explain the precise demarcation or transition between the stages of the different innovation models. Chesbrough is one of the first, however, to undertake such an effort in describing the 'erosion' of the closed innovation model and transition to the open innovation model.

It is claimed that innovation is entering a new 'era' involving deliberate and intense knowledge exchanges between firms and other organisations (Chesbrough, 2003b). At the firm level, knowledge exchanges are used as a resource or as a strategy to generate additional revenue (Gassmann, 2006). To channel these exchanges and marry them to potential internal R\&D efforts, the concept of the business model is revised and becomes central to the firm's innovation strategy (Chesbrough and Rosenbloom, 2002; Chesbrough, 2003a; Chesbrough, 2006b; Huston and Sakkab, 2007; Chesbrough and Schwartz, 2007). Thus far, the storylines on open innovation appeal to practitioners, and the majority of studies in this field read very well indeed. However, from an academic perspective the concepts are harder to grasp and there is a need for further empirical evidence based on large-scale datasets. By looking at several facets of open innovation that are relevant to innovation management and policy-making alike, and applying different measurement techniques, this book aims to bridge at least part of that gap. 
This general introduction aims to position the ideas on open innovation in the literature. To prevent distortions from the specificities of national innovation systems the focus is mainly on Belgium. In the remainder of the introduction the main ideas on open innovation are highlighted by looking at the context in which they have taken root.

The concept of open innovation is attractive on two counts. On the one hand, it pretends to offer a new analytical framework to explain the process of innovation. On the other, it promotes a management toolbox containing practical guidelines on the organisation of innovation.

Like sports and fashion, open innovation is a topic on which practitioners and scholars are divided. It has attracted a huge amount of attention. It has received a great deal of hype and in a short space of time it has improved the academics' chances of getting published. Open innovation has given rise to special issues (for example, in R\&D Management in 2006 and 2009; in Industry and Innovation in 2008 and in Technovation and Technology Analysis and Strategic Management in 2010) and takes centre stage in OECD studies (OECD, 2008c). The issue of open innovation is highly relevant, at least by contemporary standards. All of a sudden, it seems, open innovation has become the buzzphrase to explain everything there is to know in the field of innovation management and beyond. It is a textbook example of a successful crossover between management literature and economics.

But all this exposure has invited fierce criticism. Hardly surprising, given the diversity of the ideas and the fuzziness of its key concepts (Gann, 2005; Helfat, 2006). Though they haven't pronounced it dead, the critics frequently question the shelf-life of open innovation. However, although this criticism does contain elements of truth, much of it lacks a more satisfactory alternative to the majority of open innovation's central themes. In these cases, there is always the danger of throwing out the baby with the bath water.

The 'forces' or 'triggers' underlying open innovation have been discussed at length because there was a need to explain the changing innovative behaviour of enterprises. The genesis of open innovation is related closely to, even defined by, the model that precedes it: that is, closed innovation (Chesbrough, 2003a; Dahlander and Gann, 2007). The key facilitator for open innovation is the observation that knowledge is omnipresent in a firm's environment (Quinn, 2000): knowledge is distributed over various actors (von Hippel, 1988; Pisano, 1990; Lundvall, 1992; Rothaermel et al., 2006; Schilling, 2008); and knowledge is accessible through specialised markets (Arora et al., 2001; Howells, 1999; Chiesa et al., 2004; Cesaroni, 2004). The innovation process too is characterised by an 
increasingly distributed nature (Coombs et al., 2003; Acha and Cusmano, 2005; Howells et al., 2003).

Technical progress alters the knowledge requirements of firms (Pisano, 1990) and increases the complexity of the environment in which they operate. Therefore, because of this wide distribution of knowledge, firms need to tap into complementary knowledge and reach beyond their boundaries to extend their innovative activities.

A definition may well be in order before we go on to discuss the theoretical underpinnings of open innovation. Chesbrough summarises by saying that 'open innovation is the use of purposive inflows and outflows of knowledge to accelerate internal innovation, and expand the markets for external use of innovation, respectively' (Chesbrough, 2006a: 2). Though admittedly fuzzy, this definition is a good place from which to launch our discussion of the most salient theoretical underpinnings of open innovation.

Their originator formulates his ideas on open innovation according to six general principles (Chesbrough, 2003b) and, in his endeavour to demonstrate open innovation's validity as a new innovation management theory, he sums up eight elements by which it can be differentiated from the earlier, closed innovation model (Chesbrough, 2006a). Hence the - at least partial - explanation for the fuzziness of the concept: it aims to become an overarching 'theory' through which all the relevant facts can be explained, then morphs into a fully-fledged paradigm. As and when criticism is levelled, the theory adapts incrementally. The diversity of these theoretical 'building blocks' accounts for its multifaceted appearance and the rigorous task of selecting the relevant theories on which open innovation is grounded.

But what economic factors changed so dramatically that businesses were forced to adapt their innovation strategies? And how did these altered strategies influence the key characteristics of their innovation processes? How did this 'erode' the prevailing - that is, closed innovation - model? Chesbrough (2003a; 2006b) identified many factors. These can be reclassified into three categories: (i) supply side factors: a larger quantity and higher quality of skilled workers due to increased labour mobility; increased availability of intellectual property rights (IPRs); and the expansion of venture capital; (ii) technical factors: technical progress reducing the minimum scale of production to boost specialisation; the adoption of technical standards to facilitate an exchange of resources between firms; and new technologies affecting communication procedures; (iii) geographical factors: globalisation and internationalisation to extend a firm's commercialisation markets and the search environment for offshore partners and ideas. An increasing reliance on the knowledge present outside the boundaries of the firm has particular implications for those who operate in a small open economy context. Often, in this case, external knowledge 
can only be found outside the national borders (Spithoven and Teirlinck, 2006).

Chesbrough further highlights the open innovation model by couching his discourse on open innovation largely in monetary terms. Chesbrough's insights, though not explicit, imply a dynamic element that runs from closed to open innovation. Temporality, as implied by the shortening of the product cycle, should reduce the base in market turnover. Likewise, internal development costs rise and require longer depreciation periods, enlarging the base at the cost side. In addition, reducing development costs by partly externalising them does not reveal the origin of the leverage effect.

However, it is in this tying of the internal costs to the external and in the marketing of innovation through internal and external mechanisms, that the open business model acquires its meaning (Chesbrough, 2006b). Therefore, the business model is the internal mechanism for turning innovation to profit. It shows how R\&D costs relate to profit from innovation. Profit, as emphasised by classical economists such as Ricardo and Marx, is the very essence of economics. This is no different for individual firms, for whom profit is the main target (Teece, 1986; Afuah, 1998; Chesbrough, 2003a; Laursen et al., 2007). Of course, firms aim to turn a profit and so have to compete. Innovation is one of the main ways to stay competitive. Wheelwright and Clark (1992) see three elements as critical here: international competition; fragmented markets; and rapid technical progress. Since profit is the main goal, and innovation is critical to it, any measurement of open innovation would need to take it into consideration.

Turnover results from dealings on the market and costs are incurred through buying on the market. Hence the stress that Chesbrough lays on the emerging knowledge and technology markets, a phenomenon already captured by many others (Howells, 1999; Arora et al., 2001; Chiesa et al., 2004). Chesbrough (2006b) also points to the existence of a greater number of innovation intermediaries. These elements are receiving more attention (Chiesa et al., 2004; Howells, 2006), yet such market relations are captured only by traded interdependencies, as Storper (1997) calls them. In several cases, untraded interdependencies are far more important. Since the ideas on open innovation are largely cast in monetary terms - that is, traded interdependencies - their shortcomings are similar to those associated with transaction cost economics (Storper, 1997). Nonetheless, the business models concept is also intended to capture value from untraded interdependencies. These do not, however, appear in Chesbrough's ideas on open innovation. 


\section{TYPES OF OPEN INNOVATION}

Firms, like people, develop in different social and physical surroundings and so they see the world of open innovation differently (Nooteboom, 2001). The elements contained in the ideas on open innovation imply that there are different processes at work, and this leads to 'archetypes' (Gassmann and Enkel, 2004). Chesbrough (2003a) and Chesbrough and Crowther (2006) discuss these using the terms 'inbound' and 'outbound' open innovation. The former refers to the search strategy of finding external information sources to complement in-house R\&D activities; the latter stresses external paths to markets in order to commercialise the innovation. Gassmann and Enkel (2004) add a third process - the 'coupled' process - in which strategic alliances unite both inbound and outbound open innovation (see also Jacobides and Billiger, 2006). The first three chapters concentrate on firm heterogeneity and highlight the coupled process by looking at incoming knowledge spillovers, research collaboration and strategic appropriability.

Obviously, even within these 'archetypes', open innovation means different things to different writers. In addition to inbound and outbound models, Dahlander and Gann (2007) see room for open models to which informal and formal network relations are central. Laursen and Salter (2006) distinguish between the variety of external sources that channel into the firm (so-called 'breadth') and the intensity by which they are used (referred to as 'depth'). These elements offer an indication of the appreciation of network relations (Spithoven and Teirlinck, 2005).

The OECD (2008c) refines the types of open innovation in two ways. First, the degree of openness is coupled to the strategic autonomy pursued by the firm and the time horizon corresponding to it. Some activities, like inlicensing or outsourcing R\&D projects, imply that firms are able to access technology in a short space of time at the expense of losing some of their independency. This carries the potential threat of technological dependency. The traditional, vertically-integrated or 'closed' innovator can devote greater effort to time-consuming in-house development, in which case the firm's autonomy is protected against unwanted spillovers.

Second, in line with the general ideas connected to the literature on the outsourcing of R\&D, the OECD (2008c) differentiates between (a) core, peripheral and step-out activities in the target market and (b) the technology used. Some activities, such as internal R\&D, are core to the technologies used and are carried out to supply core markets; other activities, such as licensing, are peripheral to markets and technology. Finally, external corporate venturing and selling are step-out technologies offered in step-out markets. The OECD (2008c) recognises various hybrid forms in which some open innovation practices find a home. However, both of these OECD 
refinements (2008c) are convincingly argued derivatives of inbound and outbound types of open innovation. The refinements do, however, support Nooteboom's argument (2001) that firms differ in their open innovation strategies in response to different social and physical environments.

To date, the bulk of the literature on open innovation draws on case study material and is, therefore, criticised as reliant on 'anecdotal' evidence. The use of select cases may indeed point to the emergence of a new business practice. Chesbrough (2006a) acknowledges this lack of external validity. But case studies have the advantage of accommodating the richness and diversity of the concepts and dimensions; putting names to the faces of open innovation. Statistical yardsticks and econometric methods also have their drawbacks. Obviously, there is a greater need for integration and reconciliation between these two approaches to the identification of open innovation practices and their effects. This book relies heavily on statistical methods to discuss open innovation practices at some length, but does not fully capture the loss of the dynamic nature of innovation and there is a clear need for additional theory-building from case studies.

Previous paragraphs in this section have demonstrated that open innovation has not yet matured into fully-fledged theory. West et al. (2006) refer to open innovation as a 'set of practices' rather than as a theory. But this set of practices still contains blind spots and blank spaces to be filled by academics and practitioners.

It would be nothing short of a miracle if innovating ideas were to be flawless at the first attempt. Due to the many ideas that open innovation throws up, Chesbrough shoots wide of the target in several cases, but there is much work still to be done (West et al., 2006). This book addresses four areas for further development from both the theoretical and the empirical perspective. These areas include: addressing firm heterogeneity in innovation performance due to the relative fixation on firm-level analysis in general and large firms in particular; stressing the role of government in shaping corporate open innovation practices - especially in terms of networking; focusing on the implications for internal research and innovation activity of the growing tendency towards R\&D outsourcing; and highlighting the role of internal R\&D personnel in a firm's decision to engage in open innovation practices. These topics are relevant both to open innovation management in firms and to policy-making in the area of open innovation practice. They also form the backbone of this book. 


\section{PART ONE: FIRMS REACT DIFFERENTLY WHEN MANAGING OPEN INNOVATION}

The first three chapters of this book consider the issue of heterogeneity in firm innovation behaviour and performance. One drawback with empirical analyses is that, whatever the firm population, they provide information on the mean behaviour of firms. However, management science is just as interested in the behaviour at the extremes - that is, in firms that perform exceptionally well, or exceptionally poorly. This is especially relevant if we consider that open innovators are most likely to be found among the more dynamic firms (Spithoven et al., 2010). Moreover, the fiction of a 'representative firm' may be highly misleading in view of the heterogeneity of innovative behaviour. This is of particular relevance, because open innovators are likely to be found among the more dynamic firms in particular.

Therefore, analyses must enable a systematic identification of the behavioural differences between poor and strong innovative performers, with regard to both innovation output and 'black box' content when it comes to describing the external knowledge environment in which the firm operates. The challenge is to incorporate these elements in a general framework with which to analyse the relation between innovative efforts and firm performance and stress the fact that each firm has its own specificities.

The first chapter uses a structural model to explain R\&D intensity and innovative turnover and their impact on growth of turnover and employment. The empirical model is estimated using data on Belgium from the third wave Community Innovation Survey. Average regression estimates suggest that incoming knowledge spillovers, research cooperation, appropriability, workers' qualifications and export orientation all have a positive influence on R\&D investment, and, through this, on innovative turnover and employment. (For a more elaborate argumentation along this lines, see Spithoven et al., 2010.) Quantile regressions are used to look into the behaviour of different types of firms and indicate that the average impact of incoming knowledge spillovers and research cooperation tends to increase quantile by quantile, whereas the opposite holds true for appropriability. These results corroborate the predictions of open innovation theory. They suggest that innovative firms devote an increasing portion of their R\&D effort to the absorption of external knowledge, and that, among the strongest innovative performers in particular, we can find firms that are prepared to sell excess knowledge in disembodied form.

The second chapter focuses on the impact of incoming knowledge spillovers, research collaboration and strategic appropriability on research intensity and product innovative performance on a large sample of firms in 
Belgium. Again, quantile regression is applied to differentiate between weak and strong innovators. Knowledge-related variables are shown to exert an indirect effect through research intensity on innovative turnover. The impact of knowledge-related variables on research intensity differs greatly from firm to firm. It would seem that this is especially the case as regards reliance on strategic appropriability.

Since the first two chapters focus on Belgium, the third seeks external validation. We estimate a model on a country-basis to explain research intensity and innovative turnover using harmonised, firm-level data for Belgium, Germany, Norway, Spain and Portugal. We also consider alternative measures of research intensity. Average estimates show that knowledge-related variables in particular, such as incoming knowledge spillovers, research cooperation and appropriability, help explain research efforts. In-house research intensity matters most in explaining innovative turnover in the more technologically advanced countries, whereas total research intensity, which also covers expenditure on advanced machinery, does so in the less advanced. Quantile regressions indicate that the joint relative impact of incoming knowledge spillovers and research cooperation tends to increase quantile by quantile in relation to that of appropriability, and that, if anything, the impact of research intensity on innovative turnover grows in the higher quantiles. This would suggest that dynamic innovators have a more open and efficient innovation process.

\section{PART TWO: OPEN INNOVATION AND PUBLIC FUNDING PRACTICES}

Public funding can be of benefit to the innovation process and the use of external knowledge in private firms. The main argument in favour of public intervention in $\mathrm{R} \& \mathrm{D}$ and innovation processes lies in the existence of market failures. Due to these failures unintended knowledge spillovers occur and the appropriability of benefits from the innovation hampers further activity. Enterprises are then assumed to avoid R\&D investment through a lack of the necessary incentives. Therefore, support of innovation is a major ingredient of science and technology policy, which aims ultimately to enhance entrepreneurial performance and therefore stimulate economic growth.

The extent to which open innovation activities in firms benefit from public funding is less clear and is the subject of the second part of this book. The aim is to find a better understanding of the determinants and outcomes of research cooperation behaviour, with the focus on industry-science networking in particular. Special consideration is given to the potential 
influence that public funding exerts on research and innovation. Though the rationale for the public funding of innovation lies on firm theoretical ground, the empirical literature is ambiguous in its assessment of the benefits of public funding to R\&D and innovative activity, and there is little consensus on the efficacy of R\&D subsidies. This lack of consensus can be attributed to several factors. Among them we have a potential endogeneity problem, since public aid is not independent of other variables, and there is a risk of sample selection bias due to the existence of a distribution process, at the end of which a difference arises between the firms that benefit and those that do not.

Second, much of the existing literature on the effects of public funding revolves around the (mostly linear) relationship between input and output. The new ideas on open innovation, however, are well acquainted with the role of the business model in externalising innovation and making a profit from innovations not confined to the core business of the firm. In this respect, many public authorities have addressed the risk taken by enterprises to engage in innovation, or stimulated specific forms of innovative activity such as research cooperation, by providing public funding.

Chapter 4 draws on the results of the third-wave Community Innovation Survey to analyse the effects of public funding of innovation. These effects are predominantly viewed in terms of research intensity and innovative turnover. However, the way in which innovative networking at firm level indirectly influences the relationship between the funding and the effects remains a black box mystery. The analysis takes into account different sources of public funding which are regional, federal or European and uses quantile regression analysis to account for heterogeneous entrepreneurial performance. The main findings are that - in contrast with the absence of influence of funding by central government and EU funding other than the Framework Programmes - innovation funding by regional governments and by the EU Framework Programme has a positive direct impact on research intensity. Moreover, an indirect effect can also be found in the sense that this funding is positively related to and even targets involvement in research cooperation, which in turn positively affects research intensity. Therefore, funding policies can be assumed to contribute to the opening-up of the research process. In the relation between source of funding and research cooperation, both the type (industry-science versus inter-firm) and the geographical scope (domestic versus international) of cooperation matter. The indirect effect is strongest for weak innovators, indicating the highest need for public intervention to open up the research process for these innovators. In terms of innovative turnover, funding showed only an indirect influence through research intensity. The impact of the latter turned out to increase (quantile by quantile) with the strength of the innovator. 
Chapter 5 analyses the impact of public funding for innovation on research cooperation by firms. This time, use is made of data provided by the third and fourth Community Innovation Surveys (CIS3 and CIS4). The chapter applies an improved econometric technique to measure the impact of different types of public funding on different types of research cooperation. The results show that there is a substantial impact of total public funding and that its statistical significance is highest in the case of cooperation with public research organisations. A division of the total funding shows that regional government funding in Belgium has, by far, the greatest impact. There is also a more modest influence, exerted by federal government funding, mainly on cooperation with business, whereas EU funding has an impact when combined with regional funding, and mainly on cooperation with public research organisations. These differences in impact can be explained by the organisation of science and technology policy in Belgium and by the distinct aims pursued by the respective public funding agencies.

Chapter 6 analyses the behavioural additionality of subsidies based on regional and EU framework program public funding awarded to business enterprises for the 'establishment' of research cooperation between industry and science. Account having been taken of their specificities, the science component distinguishes between universities, which are considered to be more (basic) research oriented, and public research centres, which tend to be oriented more towards applied research and the commercialisation of research findings. The main result, drawing on firm-level data provided by the OECD bi-annual business R\&D surveys, is that funding by regional governments fosters the instalment of industry-science research cooperation. However, this positive effect is found only in the case of cooperation with public research centres and not with universities. This might be explained by the importance given to the prerequisite of commercialisation of research in the case of funding by regional governments. Public funding provided under the EU framework program is found not to have an impact on the instalment of industry-science cooperation, either with universities or with public research centres. This could be due the fact that EU funding is aimed at firms that are already cooperating and does not favour the set-up of new cooperation. However, the persistence over time of industry-science cooperation, as found in the analysis, highlights the importance of policymakers paying greater attention to measures that enhance the instalment of this kind of cooperation. 


\section{PART THREE: A CLOSER LOOK AT OPEN INNOVATION: R\&D OUTSOURCING}

Outsourcing activities are fuelling a heated debate among economists and the general public. Not that the purchase of goods and services from suppliers is anything new, but it is feared that the surge in outsourcing (offshoring) displaces domestic employment. Due to the rising level of education among most of the populations of the developed world, the outsourcing of low-skilled labour has not yet set alarm bells ringing. However, with the increasing division of labour at firm level, the availability of specialist knowledge outside the firm's walls, the need to remain competitive through innovation and the swift development of emerging economies such as India and China, it is believed that R\&D outsourcing could potentially affect highly-skilled employees and displace R\&D jobs.

In the past two decades there has been a remarkable increase in the R\&D outsourcing activities of firms in developed market economies. This is observed through the substantial increase in the number of R\&D partnerships, through interactions between partners and through the significant growth of firm expenditure on external R\&D. This has all taken place in a context of rapidly developing, elaborate $R \& D$ networks that combine different kinds of partnership, from straight licensing, consulting and arm's-length pure subcontracting, through more profound long-term types of subcontracting, to various forms of explicit R\&D cooperation. These partnerships involve different types of partners, such as competing firms, firms connected by vertical supplier-customer relations, and public research organisations such as universities and public research centres. And they tend increasingly to become international in nature, involving partners from different countries.

The perception of the above-mentioned tendencies has led to a gradual emergence of new views on the purpose of R\&D outsourcing and on its relation to in-house R\&D and appropriation.

In Chapter 7 a cross-section regression analysis is presented of the impact of in-house R\&D, appropriability and cooperation on the R\&D outsourcing intensity of firms, making use of data from the third and fourth Community Innovation Surveys. The results indicate that in-house R\&D has a strong positive impact on R\&D outsourcing intensity, emphasising the importance of knowledge absorptive effort and, thereby, the complementary nature of in-house and external R\&D. Strategic appropriability has a stronger positive impact on R\&D outsourcing intensity than patenting, and does so mainly through complexity of design. This suggests that the required appropriation occurs in a more informal manner than through deliberate actions of legal protection or secrecy. Finally, formal cooperation has a 
significant positive impact on R\&D outsourcing intensity, and does so mainly through cooperation with public research institutions, such as universities and research centres. This suggests that the firms in question tend to spend relatively more on external R\&D. Estimates show that this can be partly explained by the fact that public funding authorities favour cooperative industry-science relations.

Chapter 8 assesses whether firms' strategies of R\&D outsourcing determine changes in their internal R\&D employment intensity (see for additional information on this Teirlinck et al., 2010). Four strategic decisions are investigated: to start, increase, decrease or stop outsourcing. It is found that internal $\mathrm{R} \& \mathrm{D}$ employment intensity decreases when firms decide to start or to increase R\&D outsourcing. However, this finding conceals important differences according to the type and location of the contractor. Starting to outsource to research centres in the proper region seems to decrease internal R\&D employment intensity, whereas the opposite is true in the case of outsourcing to firms and universities outside the proper region.

\section{PART FOUR: THE ROLE OF HUMAN RESOURCES IN OPEN INNOVATION PRACTICES}

Nowadays economies are characterised as knowledge intensive. This implies that knowledge - in addition to labour and capital - has become an important factor of production. This knowledge is said to be either codified or tacit. If it is codified, knowledge can be traded on a specialised market, provided it is standardised and fairly priced. But tacit knowledge is embodied in the minds of people, and is part and parcel of their skills. Insights from the 'distributed' or 'open' innovation literature emphasise the need for enterprises to access external knowledge in order to perform research and innovate. One way to do so is by means of research cooperation. A research partnership may improve learning efficiency in absorbing external knowledge, thereby increasing the impact of incoming spillovers on innovative performance. It may, at the same time, provide a mechanism to reduce outgoing spillovers, by helping to internalise them.

Since R\&D and innovation are said to be ever more reliant on knowledge external to the firm, the complexity of the tasks involved in R\&D and innovation has been examined, as, in particular, have the relations between internal R\&D personnel qualification and occupation and the development and exchange of knowledge in research cooperation with the outside world. This type of research has not received much in the way of attention, which is all the more strange given that the topic of absorptive capacity (which, in 
our opinion, overly concentrates on the monetary element of R\&D intensity) figures so prominently in the current literature.

Chapter 9 looks at the functions and the qualifications of all R\&D personnel and relates these to external knowledge linkages (Spithoven and Teirlinck, 2010). Using the OECD business R\&D survey, insights are offered into the way in which R\&D outsourcing impacts on the organisation of the internal division of labour. The main conclusion is that the level of educational attainment is more important than on-the-job training if firms decide to engage in research cooperation. This implies that the skills necessary to external knowledge relation-building are largely to be found in people who already have a high degree as a threshold. Specifically, in terms of absorptive capacity, it is our finding that patent registration and innovative outputs also influence propensity to engage in knowledge development in R\&D collaboration, but not in terms of engagement of knowledge exchange in R\&D collaboration agreements.

Chapter 10 concentrates more specifically on the role of R\&D experts and managers in knowledge development and exchange in research collaboration. In line with the resource-based view and the literature on organisational absorptive capacity it is demonstrated that the absorptive capacity embodied in the experts and managers who work for the firm lowers the propensity to engage in knowledge exchange in research cooperation and increases the propensity to engage in knowledge development in research cooperation. 
André Spithoven, Peter Teirlinck, and Dirk Frantzen - 9781781953594 Downloaded from PubFactory at 04/26/2023 11:54:32AM 